\title{
Vorwort zur 6. Auflage
}

Es mag erstaunen, dass ein so umfangreiches Lehrbuch zum Sachenrecht nach doch recht kurzer Frist in neuer Auflage erscheint. Der Grund ist das großzügige Interesse des Verlages, dem ich gerne nachgekommen bin. Stoff genug gab es: Stoff zur Aktualisierung des Textes an vielen Stellen, womit die Verbesserung von Klarheit und Ordnung einherging. Was die Aktualisierung betrifft, hat die Rechtsprechung mit grundlegenden Entscheidungen fruchtbare Entwicklungsansätze geboten. Zu nennen sind beispielhaft die neuen Judikate zur Sicherungsgrundschuld, insbesondere ihrer Behandlung im Insolvenzverfahren. Immer wieder muss sich die Rechtsprechung sodann mühen mit dem Recht des Wohnungseigentums, das in heutiger Zeit als unablässiger Streitstoff eine Art von Nachbarschaftsstreitigkeiten geworden sind, die den herkömmlichen Streitigkeiten von Grundstücksnachbarn den Rang abläuft. Die von der Rechtsprechung zu vollziehenden Klärungen mussten wenigstens in den Grundlinien nachgezogen werden. Ein Hauptanliegen auch der Neuauflage sind Grundthemen des Sachenrechts, zu denen dogmatische Erkenntnisansätze der bisher dafür nicht aufgeschlossenen Rechtsprechung mit wissenschaftlicher Hartnäckigkeit anzubieten sind. Grundsätzlich bedeutsam ist die Erfassung des Wesens der dinglichen Ansprüche im Verbund der allgemeinen Schutzansprüche für Rechte, seien die Rechte absolut mit Wirkung gegenüber jedermann - auch relative Rechte sind absolut, nämlich in Bezug auf ihre Zuordnung -, seien die Rechte relativ mit Wirkung gegenüber der gebundenen Person. Als dingliche Ansprüche sind $\mathrm{zu}$ nennen die rei vindicatio in ihrem Verhältnis zu den Nebenfolgen der $\S \S 987 \mathrm{ff}$ BGB und die actio negatoria. Dogmatische Grundüberlegungen betreffen sodann die Einordnung der Regelung der BGB-Gesellschaft im Grundstücksrecht und die Zuordnung von Einreden und Rückgewähranspruch bei der Sicherungsgrundschuld. Als fruchtbar erweisen sich schließlich dogmatische Einsichten zum Eigentum auch dort, wo man es an dieser Stelle gar nicht vermutet: im Verfassungsrecht, dort nämlich, wo es um die Problematik der Abgrenzung zwischen Inhaltsbestimmung und Enteignung geht. Jeweils ist die Aufgabe die genaue Nachzeichnung der Rechtsprechung einerseits mit der Hartnäckigkeit des wissenschaftlichen Angebots andererseits.

Auch die Neuauflage widme ich meiner Frau.

Passau, im Januar 2019

Jan Wilhelm 
